\title{
U.S. Accounting Education: Misalignment With The Needs Of Small And Medium Companies
}

\author{
Megan M. Burke, Texas A\&M University - Commerce, USA
}

William R. Gandolfi, Strategic Training and Consulting Associates, USA

\begin{abstract}
This study looks to answer the question, "Does the current accounting educational system in the United States focus too heavily on the requirements of large (and SEC registered) companies at the expense of small companies and individuals who comprise the primary clientele of most practicing CPAs?" This investigation surveys CPAs regarding their perceptions of the focus of their accounting education. The results of the survey suggest that the current accounting curriculum does not focus enough on the accounting needs of small businesses. Suggestions for improvement in the curriculum include adding small business coverage in accounting courses, including more general business courses, requiring more hands-on practice with the material and adding internships with smaller firms.
\end{abstract}

Keywords: Accounting Education; Small Business; Accounting Curriculum

\section{INTRODUCTION}

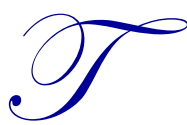

he objective of this paper is to foster further evaluation and discussion of the adequacy of coverage in the United States' accounting educational system regarding the accounting needs of small- and medium-sized businesses (SMBs) and individuals. While the coverage in most accounting courses skews toward issues relating to large business, the majority of accounting graduates work with SMBs and individuals.

The relevance of this topic emanates from the observation that the collegiate system may be preparing students who can pass the CPA exam and work in a large firm environment, but struggle when confronted with the work realities that face smaller firms. Directly addressing the needs of their primary clients, handling smaller clients on behalf of larger firms, and dealing with the demands of running a small practice are issues that an individual who is prepared to work in a large firm environment may be ill equipped to handle.

The literature covers many of the issues presented in this analysis, most notably Bedford et al. (1986), which succinctly stated, "(w)e still continue to teach accounting as if it is and will continue to be practiced in hierarchical, bureaucratic organizations." The main implication being that the educational system was teaching accounting for a different era, one in which the CPA was considered strictly an expert in the technical aspects of accounting and considered as a role to handle issues which were generally beyond the understanding of corporate managers. CPAs were focused on corporate accounting issues and were not involved in other aspects of the business. They also had little to do with private individuals and their needs, with the notable exception being matters of taxation (Bedford, et al., 1986). Today's CPAs are more involved with businesses and individuals and, from a small practice perspective, handle a wide range of issues that are not addressed from an educational perspective.

The paper proceeds with an initial framing of the issue through a review of existing literature and the work environment of today's accountants. The balance of paper will cover the research methodology, the findings, 
interpretations of the findings, and suggestions for curriculum improvement.

\section{LITERATURE REVIEW}

According to the U.S. Bureau of Labor Statistics, there are over 1.1 million employees in accounting and auditing (Bureau of Labor Statistics, 2013), with approximately one-third of those working in public accounting. A census conducted in 2001 concluded that the national average for CPA firm employment was seven associates, with large metropolitan area-based firms only averaging six employees (Zlatkovich \& Putnam, 2001). Tiburon Advisors, a financial market research and strategy group, found that $79 \%$ of CPA's work with small firms and individuals (Tiburon Strategic Advisors, 2004). While large firms exert a great deal of influence and gather a majority of the attention, the numbers indicate that the bulk of accountants and CPAs do not work with large public accounting firms, but work either in industry or for smaller CPA firms.

To further illustrate the issue, if one looks at the mix of revenue generated by firms of varying sizes, it becomes clear that much of the higher-level technical training (which falls mainly into large company and SEC regulated audits) is utilized in a relatively diminutive part of the business. Between four and sixteen percent of small firm revenue (under one million dollars in volume) is derived from audit and attestation services (Zimmermann \& Flaherty, 1997). In contrast, firms doing over one million dollars in volume derive more than one-fifth of their revenue from audit and attestation (Zimmermann \& Murray, 1999). Furthermore, large firms normally perform the taxes of large corporations, multi-nationals, and others that are highly complex in nature, and have access to specialists and other resources not available to small firms. While most CPA firms do similar work, it is the level and technical nature of the work done by large companies that may be the issue (Willcoxson \& Laing, 2010).

These facts serve to inform our first hypothesis:

H1: The US accounting education system does not provide enough coverage of small business accounting for the needs of practicing accountants.

There has been much discussion within literature regarding the future of accounting education and the direction it should take. There seems to be a trend toward recommending the addition of skills and addressing issues within accounting education curricula that were discussed in the above sections (Braun \& Mauldin, 2012), but it seems to end there. The trade associations have sponsored commissions and reports in this area, but not all were met with unanimous support. Initially, the AICPA had considerable differences of opinions with the American Accounting Association-sponsored Bedford report (AICPA responds to AAA report on future accounting education, 1986).

The AICPA and the AAA have tried to address this matter by co-sponsoring the Pathways Commission's (Accounting Education Change Commission, 1991) report which recommended numerous changes to the accounting higher education system. The report lists many goals but has very little detail on how to go about directly attaining them (Behn, et al., 2012). In reality, the Pathways report falls more under the concept of a framework for development rather than a set of substantial recommendations.

In a study commissioned by the Institute of Management Accountants that surveyed current accounting practitioners and educators, it was discovered that a majority of the respondents would not obtain an accounting MS degree if completing their education today (Albrecht \& Slack, 2000). In the study, the preponderance of interviewees favored obtaining an MBA over a degree in accounting. The primary reason given for this was that the business world has changed drastically while accounting education has not (Albrecht \& Slack, 2000).

\section{METHODOLOGY}

A multi-question survey was used to address the research hypothesis. The survey was conducted in person, by phone, and by email. The survey asked for demographic information including years of experience as a CPA, educational background, position within the firm, size of the firm for whom they work, and allocation of client base across client size. The participants were asked if they felt their academic preparation was too concentrated, just 
right, or not enough related to Small Business, Medium Business, Large Business, Sec Listed/Traded Company, Governmental Units, Non-Profits, and Individuals. Participants were also asked questions relating to soft skills and practical skills during their academic preparation.

\section{Participants}

The participants were all CPAs and were randomly selected from attendees entering a series of local and state (regional within the state) meetings for CPAs. Selection was made by the first person entering the meeting area and upon completion of that interview, the next person entering was selected. Identical questionnaires were used in phone interviews with CPA firms in the Northern part of Illinois. The questionnaires were also mailed to multiple firms throughout Illinois. Any responses returned by non-CPAs were rejected for the purpose of this study.

In total, 267 surveys were conducted from which 39 responses were gathered. Ninety-eight questionnaires were sent out by mail, seven of which were completed, and 169 phone and in-person interviews were conducted, with 32 responses gathered. Of the 39 responses, three were rejected due to not being CPAs, leaving 36 surveys utilized in the analysis.

The participants tended to be experienced CPAs with $78 \%$ having six or more years of experience. They predominantly held a Master of Science or Arts in Accounting (MSA) or an MBA (69\% combined), with an additional 11\% holding terminal degrees, and 19\% holding a Bachelor of Sciences or Arts in Accounting (BSA) as their highest degree. The participants were primarily partners, owners, or managers (44\%), with $28 \%$ staff accountants, $14 \%$ holding the position of $\mathrm{CFO}$, and the balance split between interns and other executives.

Consistent with data from the Bureau of Labor Statistics and the Tiburon report, a majority of participants worked for small firms (53\%), with $15 \%$ at medium-sized firms, and $32 \%$ at large firms. On average, the respondents spend approximately $31 \%$ of their time working with individuals, $26 \%$ with small businesses, $23 \%$ working with medium-sized businesses, $10 \%$ with large and SEC-listed companies, and $10 \%$ with governmental and not-for-profit entities.

\section{RESULTS}

The survey question, "(w)as your education sufficient in the area of small business?" addresses the primary hypothesis and is shown in Table 1. Sixty-one percent of the respondents believe that their academic preparation relating to small business was insufficient, $36 \%$ said it was sufficient, and only $3 \%$ thought that coverage was too concentrated. Additionally, the majority thought that medium businesses, large businesses and SEC-listed companies were sufficiently covered. Respondents were split on their perception of coverage of individuals. Approximately two-thirds of the participants felt that coverage of governmental and non-for-profit topics was insufficient.

Table 1: Sufficiency Of Coverage By Type In The Subject's Education

\begin{tabular}{|l|c|c|c|}
\hline Type of Business & Over Covered & Correct & Insufficient \\
\hline Small Business & $2.78 \%$ & $36.11 \%$ & $61.11 \%$ \\
\hline Medium Business & $5.56 \%$ & $63.89 \%$ & $30.56 \%$ \\
\hline Large Business & $25.00 \%$ & $61.11 \%$ & $13.89 \%$ \\
\hline SEC Listed/Traded & $27.78 \%$ & $52.78 \%$ & $19.44 \%$ \\
\hline Government & $0.00 \%$ & $36.11 \%$ & $63.89 \%$ \\
\hline Non-Profit & $0.00 \%$ & $33.33 \%$ & $66.67 \%$ \\
\hline Individuals & $5.88 \%$ & $47.06 \%$ & $47.06 \%$ \\
\hline
\end{tabular}

Table 2 presents the perception of educational coverage of small business accounting based on respondent experience and shows that $81 \%$ of the experienced CPAs (over 11 years) feel that their education was insufficient. Those with lesser experience were split on this point. However, $67 \%$ of the least experienced (1 year or less) feel that their education related to small business accounting was insufficient. For the remaining types of businesses, the responses were similar across experience levels and correspond to the results in Table 1. 
Table 2: Years Of Experience To Sufficiency Of Small Business Coverage

\begin{tabular}{|l|c|c|c|}
\hline Years & Too Much & Correct & Not Enough \\
\hline 1 or less & $0.00 \%$ & $33.33 \%$ & $66.67 \%$ \\
\hline 2 to 5 & $20.00 \%$ & $40.00 \%$ & $40.00 \%$ \\
\hline 6 to 10 & $0.00 \%$ & $58.33 \%$ & $41.67 \%$ \\
\hline 11 or more & $0.00 \%$ & $18.75 \%$ & $81.25 \%$ \\
\hline
\end{tabular}

Comparing education level to sufficiency of coverage of small businesses, $86 \%$ of respondents with a Bachelor's degree felt that coverage was insufficient as illustrated in Table 3. A majority of this group also believe there is an overemphasis of coverage of large businesses and SEC firms. Those with graduate degrees agreed that there was not enough coverage of small business accounting but felt that there was sufficient accounting coverage for large business and SEC firms. Regardless of education level, a majority of respondents believe there is adequate educational coverage of medium-sized firms and individuals and there is insufficient coverage of governmental and not-for-profit entities.

Table 3: Education Level To Sufficiency Of Small Business Coverage

\begin{tabular}{|l|c|c|c|}
\hline Education & Too Much & Correct & Not Enough \\
\hline BS & $0.00 \%$ & $14.29 \%$ & $85.71 \%$ \\
\hline MSA & $6.25 \%$ & $37.50 \%$ & $56.25 \%$ \\
\hline Terminal & $0.00 \%$ & $44.44 \%$ & $55.56 \%$ \\
\hline
\end{tabular}

Table 4 presents the results based on position within the firm. When evaluating the educational coverage of small business accounting by position within the firm, interns were split between believing coverage was sufficient and that coverage was lacking. Staff level associates through partner/owners felt that accounting education coverage for small business was insufficient, while CFO's and other executives felt that coverage was sufficient. In general, participants in all positions felt that educational coverage of medium business accounting, large business accounting and accounting for individuals was appropriate. Forty-four percent of the partner/owner group felt that educational coverage of accounting for SEC-listed firms was insufficient. Interns through owners felt that educational coverage was lacking for governmental and not-for-profit entities, while CFO's and executives felt the coverage was sufficient.

Table 4: Position To Sufficiency Of Small Business Coverage

\begin{tabular}{|l|c|c|c|}
\hline Position & Too Much & Correct & Not Enough \\
\hline Intern & $0.00 \%$ & $50.00 \%$ & $50.00 \%$ \\
\hline Staff & $10.00 \%$ & $30.00 \%$ & $60.00 \%$ \\
\hline Mgr/Ptr/Owner & $0.00 \%$ & $25.00 \%$ & $75.00 \%$ \\
\hline CFO & $0.00 \%$ & $60.00 \%$ & $40.00 \%$ \\
\hline Other Exec & $0.00 \%$ & $66.67 \%$ & $33.33 \%$ \\
\hline
\end{tabular}

As Table 5 illustrates, a majority of participants working at small to medium-sized firms felt that coverage of accounting for small businesses was insufficient, while half of the participants from large firms felt that the amount of educational coverage was adequate. Those from small firms believed there was too much focus given large firm accounting, while those at medium and large firms felt that the educational coverage was the right amount. Participants from small firms also felt that there was too much coverage of accounting for SEC-listed companies, while those from medium-sized firms felt the coverage was the right amount, and those from large firms were split between the belief that the coverage was sufficient.

Table 5: Firm Size To Sufficiency Of Small Business Coverage

\begin{tabular}{|l|c|c|c|}
\hline Firm Size & Too Much & Correct & Not Enough \\
\hline Small & $0.00 \%$ & $22.22 \%$ & $77.78 \%$ \\
\hline Medium & $0.00 \%$ & $37.50 \%$ & $62.50 \%$ \\
\hline Large & $12.50 \%$ & $50.00 \%$ & $37.50 \%$ \\
\hline
\end{tabular}

In evaluating participants' responses based on the types of clients that receive the majority of their time, it 
was revealed that those who work primarily with small businesses and individuals believe that there is not enough coverage of small business accounting as shown in Table 6. Of those who spend a majority of their time working with large businesses, $40 \%$ believe that coverage of large business accounting is insufficient and $60 \%$ believe that coverage of accounting for SEC listed firms is insufficient. However, a majority of participants who spend their time on individual accounting believe that there is too much coverage of accounting for large and SEC-listed firms. In regard to the sufficiency of coverage of individual accounting matters, $47 \%$ of those who work with individuals believe there is not enough coverage and $40 \%$ of those who work with large firms believe there is too much coverage.

Table 6: Time On Clients To Sufficiency Of Small Business Coverage

\begin{tabular}{|l|c|c|c|}
\hline Client Type & Too Much & Correct & Not Enough \\
\hline Small & $0.00 \%$ & $38.46 \%$ & $61.54 \%$ \\
\hline Large & $20.00 \%$ & $40.00 \%$ & $40.00 \%$ \\
\hline Individuals & $0.00 \%$ & $20.00 \%$ & $80.00 \%$ \\
\hline Gov't/NFP & $0.00 \%$ & $100.00 \%$ & $0.00 \%$ \\
\hline
\end{tabular}

\section{INTERPRETATION OF FINDINGS}

The findings of this study support the authors' hypothesis that that current US accounting education system does not provide enough coverage of small business needs. Sixty-one percent of respondents believe that the coverage of small business matters was insufficient during their academic preparation. Additionally, the participants spend $48 \%$ of their time working with SMB, $32 \%$ with individuals and only $10 \%$ of their time on large and SEClisted companies, on average. The needs of today's CPA do not match with the current curriculum offerings.

The findings are reinforced by the responses to the open-ended questions on the surveys. Specifically, when asked about specific topics with insufficient coverage, participants said:

... a course in small business accounting and their needs ... partners, LLP, and LLC

...information on S-Corps, LLCs, LLPs, Sole Proprietors, and partnerships

... small CPA businesses; individuals, small companies, writing and speaking, how to efficiently find the information you need

Add courses in consulting, mainly for small businesses. ... they are looking for a lot more from their CPA today and we are not really trained to provide it. ...This should cover all aspects of a small business from operations to finance...[to] the psychological or sociological aspects of working with business owners...

...how to do general accounting for ...small companies and individuals. Less on high-level technical issues and theories ...A course in how to look up the technical information... covering how to apply and use the information when you find it.

Participants were also asked about areas that were covered too heavily, with the following responses:

Should be more of an overview of large business applications and detailed study of small and medium companies; most (accountants) I know do not work with large corporations, only big regional and up firms do.

Less time on mergers and foreign currency in advanced accounting, more on the little guy's needs

$M \& A$, foreign business and international currency issues are covered in far too much detail for most CPAs.

Technical Skills, in general, were way too heavily covered; most items covered in upper level classes are seldom used, if at all, and could be looked up. More on research and real life examples with practical applications. 
Audit and finance on the SEC requirements do none in practice; only big firms do and they retrain anyway.

Advanced accounting; almost all of it I never use.

Too much concentration from intermediate on covering mergers, stock options, and related issues; do not use in my practice.

Based on the responses from the participants, it is clear that there is a misalignment between the needs of practicing CPA's and the US accounting education system. The Bedford Report put forth the concept that accounting education may be outdated and locked in the past. The open-ended questions reinforce this.

Too much memorization of rules and regulations

More doing and less memorizing. ...stress research and application rather than be based so heavily on rote memorization. Require courses on non-profit and government applications.

...rote memorization of information rather than learning the theory, practice, and application of it

Technology and simulation of actual business operations... The role of the CPA has changed from what it was twenty-five years ago. Today we are required to be more familiar with all aspects of the client's business and are not just a ... bookkeeper, but someone who can actually provide assistance with the clients' overall business needs.

The list of skills that the respondents feel they need, along with observations regarding areas that receive a disproportionate amount of attention, bolster the findings of the Bedford report. The bureaucratic hierarchy of large firms mentioned in the report does not require many of the skills that are mentioned in the open-ended questions responses. This observation, coupled with the general view that many programs are aligned to address the requirements of large firms and the needs of passing the CPA exam, presents a challenge to the existing accounting educational system. To address the educational gaps regarding accounting for small and medium-sized firms, the existing curricula will need to be modified and enhanced.

\section{SUGGESTIONS FOR CURRICULUM IMPROVEMENT}

The most obvious adjustment to the current curriculum would be to increase the coverage of small business accounting needs. Sections on sole proprietorships, smaller partnerships, and S-Corporations could be added to Intermediate Accounting, Advanced Accounting, and taxation courses. As small businesses expect accountants to consult on a wide range of business matters, general business courses could be added to the curriculum to focus on the consulting needs of small businesses. Specifically, the subjects stated:

Small business requirements... entrepreneurs and how they function, team building, additional micro and macroeconomics, more on finance to assist clients with their needs, theft prevention and fraud detection, communications, and leadership.

... family businesses and sole proprietorship needs and wants.

More general business and management classes should be included in the requirements for an accounting degree.

Financial and tax advice... These are both areas that are important to my practice's success....

Another improvement to the curriculum would be to include more hands-on, practical experience in bookkeeping and developing financial statements from scratch. These basic skills are taught more as theory, which, while consistent with an educational system's purpose, does not provide the amount of practical application that would allow a recent graduate to perform at the required level within a small or medium-sized firm setting. A number of respondents stressed the importance of adding the practical exercises to courses rather than just theory and concepts. 
How could I have gone through a BS and MS in accounting and never once had to take information from the transaction all the way to the financial statements. I was given information and asked to prepare simplistic financials or asked to do detailed parts of statements, but that is not like having to start from nothing. Somewhere in the system, a course should give you the chance to do what you have to do in real life, take a set of information, prepare the financials, and then have to figure out why things do not balance or come out right. Perhaps it could use a QB (QuickBooks) actual set of books and put together the reports, or take what QB generates as reports and have to determine where the problems are. Clients often have very messy, poor quality books and we have to fix them. We are never given practice in how to do this. Instead, I memorized reams of information to pass tests and then promptly forgot it all. I would have remembered the process of digging through information and finding problems, looking up what was needed, and so on; if I had a chance to learn it in college rather than the hard way in someone's books.

Beginning and intermediate accounting covered a lot of ground and did so with lecture and problems. What they did not do was provide the opportunity to apply the information. Nothing was that difficult in these courses, but actually applying the principles and doing the work was a different story. I felt very lost when I had to take a client's books and run them through the cycles from start to finish. There needs to be some type of actual application that takes the information from the event and works it through to the final effect it has on the BS and P/L. Textbook problems may do this in bits and pieces, but never in totality, which is a different situation. This is where I had issues starting out seeing how all things fit and even where to start, in some cases, with my clients.

An additional area of improvement would be for programs and students to secure additional internship or shadowing opportunities with accounting firms who service small businesses. This would provide students with a more realistic view of the needs of small businesses.

A final suggestion would be to offer separate educational paths to meet the needs and requirements based on the expected client base of students upon graduation. One curriculum could address the specific needs and requirements of large firm accounting and cover the topics and technical skills that a successful CPA candidate for a large firm would be expected to know and possess. A separate curriculum could address the requirements of those who need the skills and knowledge necessary to run their own practice or be a successful part of a small or mediumsized firm. In this way, programs would have the flexibility to cover topics specific to a firm's size in greater detail, while not sacrificing the time required to prepare individuals to take and pass the CPA exam.

\section{CONCLUSION}

There is a clear a gap between the accounting needs of small and medium businesses and the academic preparation that is provided by the educational system. A majority of CPA's work with small businesses and individuals, yet a large portion of the survey respondents in this study believe their academic preparation regarding small business accounting was insufficient. To meet the needs of practicing accountants and their primary clientele, the US accounting education system should consider adding courses or coverage of small business accounting topics, and include general business courses to facilitate the role of accountant as a consultant for small businesses and individuals. Additionally, programs should increase the practical, hands-on exposure in courses and work to increase internship opportunities with firms who service small business clients. Taking these still will help bridge the gap between accounting education and the practical experience of CPAs.

\section{AUTHOR INFORMATION}

Megan M. Burke, Ph.D., is an Assistant Professor of Accounting at Texas A\&M University-Commerce. Her research interests include taxation and accounting education. Email: Megan.Burke@tamuc.edu. (Corresponding author)

William Gandolfi is the president of Strategic Training and Consulting Associates (STC). He provides consulting services in accounting, finance, business startup, efficiency, and business structural and process re-engineering. He has an MBA and an MS in Accounting from Texas A\&M University-Commerce. Email: wrgandoli@ConsultSTC.com. 


\section{REFERENCES}

1. Accounting Education Change Commission. (1991). Issues Statement Number 2. Sarasota: American Accounting Association.

2. AECC Urges Decoupling of Academic Studies and Professional Accounting Examination Preparation: Issues Statement No. 2. (1991). Issues in Accounting Education, 6(2), 313-314.

3. AICPA responds to AAA report on future accounting education. (1986). Journal of Accountancy, 162(4), 26-27.

4. Albrecht, W. S., \& Slack, R. (2000). Accounting education: Charting the course through a perilous future (Accounting education series) (Vol. 16). Sarasota, FL: American Accounting Associtation.

5. $\quad$ Bedford, N., Bartholomew, E. E., Bowsher, C. A., Brown, A. L., Davidson, S., Horngren, C. T., \& Wheeler, J. T. (1986). Future accounting education: preparing for the expanding profession. American Accounting Association.

6. Behn, B. K., Ezzell, W. F., Murphy, L. A., Rayburn, J. D., Stith, M. T., \& Strawser, J. R. (2012). The Pathways Commission on accounting higher education: Charting a national strategy for the next generation of accountants. Issues in Accounting Education, 27(3), 595-600. doi:10.2308/iace-10300.

7. Booth, W. C., Colomb, G. G., \& Williams, J. M. (2008). The craft of research. Chicago: The Universty of Chicago Press.

8. Braun, R. L., \& Mauldin, S. (2012). From practice to the classroom. Journal of Accountancy, 214(4), 4045 .

9. Bui, B., \& Porter, B. (2010). The expectation-performance gap in accounting education: An exploratory study. Accounting Education, 19(1/2), 23-50. doi:10.1080/09639280902875556.

10. Bureau of Labor Statistics. (2013, May). Occupational Employment Statistics. Retrieved from http://www.bls.gov/oes/current/oes132011.htm.

11. Chang, C.-C., Landis, M., \& Yu, S. C. (2011). Investing in accounting: A call for professional involvement in higher education. American Journal of Business Education, 4(2), 27-32.

12. Harper, B. J., \& Churchill, N. C. (1987). Serving small business: what CPAs should know. Journal of Accountancy, 163(6), 120-127.

13. Jackling, B., \& De Lange, P. (2009). Do accounting graduates' skills meet the expectations of employers? A matter of convergence or divergence. Accounting Education, 18(4/5), 369-385. doi:10.1080/09639280902719341.

14. Kermis, G., \& Kermis, M. (2010). Professional presence and soft skills: A role for accounting education. Journal of Instructional Pedagogies, 2, 1-10.

15. Kushniroff, M. C. (2012). Where do we go to ensure the continuation of accounting education? Journal of Accounting \& Finance, 12(4), 110-122.

16. Low, M. S., \& Liu, C. (2013). Accounting education and the provision of soft skills: Implications of the recent NZICA CA academic requirement changes. E-Journal of Business Education \& Scholarship of Teaching, 7(1), 1-33.

17. Purdy, D., \& Pleis, L. M. (2012). Small business accounting: Preparing future accountants through a new graduate accounting course. Allied Academies International Conference. 17(2), pp. 15-15. Academy of Accounting \& Financial Studies.

18. Sleeter, D. (2013). What small businesses want from their accounting professional. CPA Practice Advisor, 23(4), 18-18.

19. Thomson, J. C. (2009). Closing the accounting talent gap. CPA Journal, 79(12), 13-14.

20. Tiburon Strategic Advisors. (2004, December). CPA Market Analysis. Retrieved from http://www.tiburonadvisors.com/04.12.03\%20-\%20Tiburon\%20Research\%20Release\%20-

\%20CPA\%20Market\%20Overview.html.

21. United States Department of Labor. (2009, May). Occupational Employment and Wages. Retrieved from Occupational Employment Statistics: http://www.bls.gov/oes/2009/may/oes132011.htm.

22. Walker, K. B., \& Ainsworth, P. L. (2001). Developing a process approach in the business core curriculum. Issues in Accounting Education, 16(1), 41-66.

23. What do small businesess need from CPAs? (1995). Journal of Accountancy, 179(5), 20-21.

24. Willcoxson, L. W., \& Laing, G. K. (2010). A whole-of-program approach to the development of generic and professional skills in a university accounting program. Accounting Education, 19(1-2), 65-91. 
doi:10.1080/09639280902886082.

25. Wilson, R. M. (2011). Alignment in accounting education and training. Accounting Education, 20(1), 3-16. doi:10.1080/09639284.2011.555940.

26. Zikmund, W. G., \& Griffin, M. (2010). Business research methods (8th ed.). Mason, OH: Cengage Learning.

27. Zimmermann, R. A., \& Flaherty, D. J. (1997). National MAP survey results. Management of an Accounting Practice, 184, 49-52.

28. Zimmermann, R. A., \& Murray, M. A. (1999). The national results of the 1998 Management of Accounting Practice Survey. CPA Journal, 69(7), 40.

29. Zlatkovich, C. P., \& Putnam, K. B. (2001). How does your firm compare? CPA Journal, 71(2), 36-41. 


\section{NOTES}

